\title{
DUAS ESPÉCIES NOVAS DE PSYLLOBORA CHEVROLAT, 1837 (COLEOPTERA, COCCINELLIDAE) ${ }^{1}$
}

Lúcia Massutti de Almeida ${ }^{2}$

\begin{abstract}
Psyllobora abancayana $s p$. n. and P. equatoriana sp. n. are described and illustrated.
\end{abstract}

Psyllobora abancayana sp. n.

(Figs. 1-4)

Diagnose: Cabeça com clípeo fundido à fronte sem depressão ou linha de sutura. Mandíbulas robustas com bordo externo em ângulo e mola com dente. Corpo arredondado, glabro com tegumento amarelado leitoso e máculas marrons. Pronoto com quatro máculas: duas mais regulares e menores no ápice e duas irregularidades, e pouco maiores que as primeiras na base e mais afastadas uma da outra. Élitro com 6 máculas (Fig. 1). Uma sobre o calo umeral, quatro máculas separadas irregulares formando uma faixa transversal interrompida no meío do élitro e uma mácula pequena no lado externo, subapical. Metastemo e região central do 1 . . esterno abdominal visível marrom escuro.

Genitália: Macho: Lobo médio de lados paralelos, estreitando-se para o ápice, este em forma de seta larga. Parâmetros pouco menores que o lobo médio, com cerdas longas (Fig. 2). Sifão sem prolongamento apical, com dois processos laterais logo abaixo do ápice (Fig. 3).

Fêmea: Espermateca ramificada, na extremidade de sua curvatura pouco maior que o primeiro esterno abdominal visível, infundíbulo cônico (Fig. 4).

Medidas: 5,42-5,83 mm de comprimento e 4,33-4,83 $\mathrm{mm}$ de largura.

Variações: A mácula sub-apical do élitro pode estar ausente e uma outra mácula apical pode ocorrer, maior que a sub-apical.

Comentários: Esta espécie é muito próxima de Psyllobora lata porém dela difere por apresentar as máculas da faixa transversal do meio do élitro bem separadas; pela ausencia da mácula apical; pelo tamanho e forma do ápice do lobo médio; e pelo tamanho do parâmero que nesta espécie é menor que o lobo médio.

Material Tipo: Holótipo de Abancay, Peru, de 6-III-1965, coletado por Ross \& Michelbacker depositado no United States National Museum (USNM) e 2 parátipos no Departamento de Zoologia da Universidade Federal do Paraná (DZUP).

1. Contribuição n? 680 do Depto. Zoologia da UFPR.

2. Pós-Graduação, doutorado, Depto. Zoologia, UFPR, Caixa Postal 19.020, 81.504, Curitiba, Paraná, Brasil. 
Revta bras. Zool.
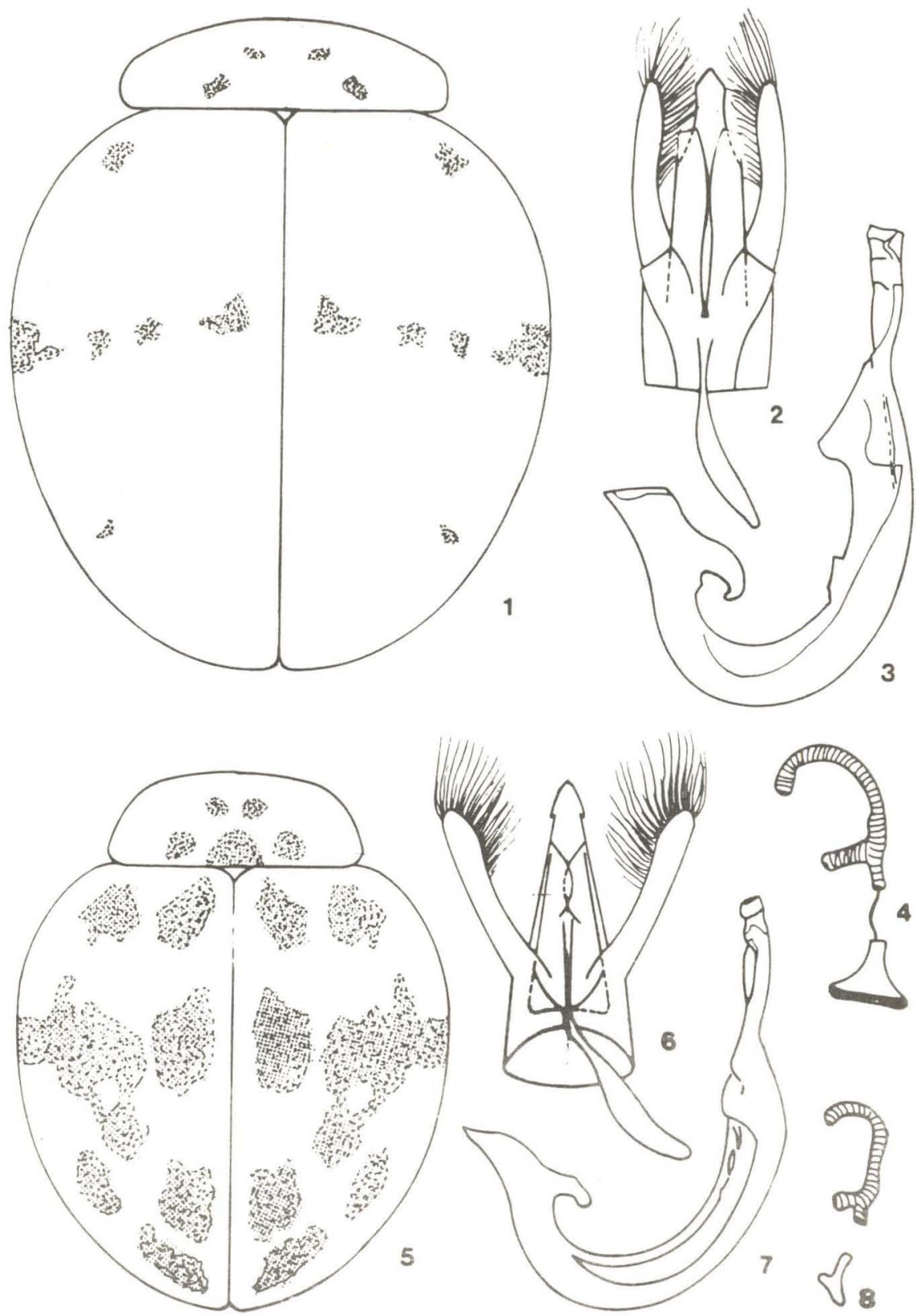

Figs. 1-8. Psyllobora abancayana sp^. 1. pronoto e élitros; 2. lobo médio; 3. sifāo; 4. espermateca; Psyllobora equatoriana sp.n. 5. pronoto e élitros; 6 . lobo médio; 7. sifāo; 8 . espermateca. 


\section{Psyllobora equatoriana sp. $\mathrm{n}$.}

(Figs. 5-8)

Diagnose: Cabeça com clípeo fundido a fronte sem depressão ou linha de sutura. Mandíbulas com bordo externo curvo, mola com dente. Corpo arredondado, glabro, com tegumento amarelado leitoso e máculas marrons. Pronoto com 5 máculas: 2 anteriores mais unidas, arredondadas, 3 na base, as externas arredondadas e a mediana triangular. Élitro com 9 máculas (Fig. 5). Duas sub-basilares: uma próxima à sutura, uma no centro de bordo anterior ponteagudo e prolongada até a margem externa do élitro. A segunda metade do élitro com 4 máculas dispostas em cruz: a $1^{\text {a }}$ da cruz ligada a mácula do meio da faixa transversal acima, das duas laterais da cruz, uma próxima da sutura e outra do bordo externo do élitro. A última da cruz, alongada, no ápice đu éitro. Metasterno e parte central dos dois primeiros esternos abdominais visíveis negros.

Genitália. Machos: Lobo médio largo na base, com ápice em seta larga, com parâmeros pouco menores (Fig. 6). Sifão sem prolongamento apical, e com projeções laterais largas de bordos arredondados (Fig. 7).

Fêmeas: Espermateca ramificada, nas extremidades de sua curvatura maior que o 1. esterno abdominal visível, infundíbulo cônico (Fig. 8).

Medidas: 4,03-5,19 mm de comprimento; 3,33-4,42 mm de largura.

Varią̧ôes: As trés máculas basais do pronoto podem estar unidas. A mácula elitral próxima da sutura pode estar unida às demais máculas transversais formando uma faixa contínua. A mácula anterior da cruz pode estar isolada da faixa anterior.

Comentários: Espécie próxima de $P$. lata e $P$. abancayana e delas difere por apresentar comprimento menor; maior número de máculas elitrais; e ápice do lobo médio em seta, porém com dois pequenos processos laterais.

Material Tipo: Holótipo de Imbabura (Chachimbrio), Equador, XI/1984, E. Martinez, depositado na Pontifícia Universidade Católica do Equador (PUCE). Parátipos: Equador, 20/XI/1984, M. Garcia, 1 ex.; XI/1984, M. Rivera, 1 ex.; 19/XI/1984, M. Garcia, 1 ex.; 17/XI/1984, Santamaria, 1 ex., depositados no PUCE e no Departamento de Zoologia da UFPR (DZUP).

\section{REFERENCIAS}

ALMEIDA, L.M. \& MARINONI, R.C. 1983. Contribuição do conhecimenło do Gênero Psyllobora Chevrolat, 1837. (Coleoptera-Coccinellidae). Revta. bras. Ent., 27(2):165-175.

ALMEIDA, L.M. 1987. Estudo de 17 espécies do gênero Psyllobora Chevrolat, 1837 (Coleoptera Coccinellidae). Acta. Biol. Par. 14(1,2,3,4):47-102.

BLACKWELDER, R.E. 1945. Checklist of the coleopterous insects of Mexico, Central America, the West Indies, and South America. Bull. U.S. Natn. Mus. 185(3):343-550.

BLACKWELDER, R.E. 1957. Idem, ibidem, 185(6):V-VII, 927-1492.

CHEVROLAT, L.A.A. 1847. In d'Orbigny, Dict. Univ. Hist. Nat. 10:606.

CROTCH, G.R. 1851. List of Coccinellidae. 1-8. Cambridge.

CROTCH, G.R. 1873. Revision of the Coccinellidae of the United States. Trans. Am. Ent. Soc. 4 : 363-382.

CROTCH, G.R. 1874. A Revision of the Coleopterous family Coccinellidae. E.W. Janson. London, 1-311.

GORDON, R.D. 1987. A catalogue of the Crotch collection of Coccinellidae (Coleoptera). Occ. Pap. Syst. Ent. 25:16-17. 
Revta bras. Zool.

KURSCHEFSKY, R. 1932. Coleopterorum Catalogus. XVI(120), Coccinellidae II:565-570. W. Junk. Berlin.

LIMA, A.M.C. 1937. Espécies de Psyllobora.(Col. Coccinellidae). Mem. Inst. Oswaldo Cruz. 32:1-12. 2 figs. 3 est.

MULSANT, E. 1850. Species des Coléoptéres Triméres Sécuripalpes. Lyon. 1-1104.

MULSANT, E. 1866-67. Monographie des Coccinellides. M. Savy. Lyon. 1-290. (Mém. L'Acad. Imp. Lyon. 16, 1866-67). 